\title{
Comparative Effect of Mobilization, Low Dye Taping and Faradic Foot Bath in Subjects with Flat Foot - A Randomised Clinical Trial
}

\author{
Charleen D'Silva ${ }^{1}$, Santosh Metgud ${ }^{2}$, Anand Heggannavar ${ }^{3}$ \\ ${ }^{I}$ (PG Student, Department of Orthopedic Manual Therapy, KLEU Institute of Physiotherapy, KLE University, \\ India) \\ ${ }^{2}$ (Associate Professor, Department of Orthopedic Manual Therapy, KLEU Institute of Physiotherapy, KLE \\ University, India) \\ ${ }_{3}^{3}$ (Associate Professor, Department of Orthopedic Manual Therapy, KLEU Institute of Physiotherapy, KLE \\ University, India)
}

\begin{abstract}
Background: Adult acquired flatfoot and arch deformities result from disruption of the supporting ligaments as well as from muscle weakness or tightness leading to direct impairments in the arch. But as the condition progresses it leads to various biomechanical alterations within an individual which further hampers the daily functioning of an individual. The purpose of the study was to evaluate and compare the effects of talo-navicular mobilization, low dye taping and faradic foot bath using navicular drop test and arch index in subjects with functional flat foot.

Methods: 51 subjects with functional flat feet aged between 18 to 30 years were included. The subjects were randomly allocated, with 17 subjects in each group and were assigned to 3 groups: Talo-navicular mobilization (Group A), Low dye taping (Group B) and Faradic foot bath (Group C). Demographic data was collected and navicular drop height and arch index was measured pre and post the 3 weeks intervention.

Results: The intra group comparison results showed a decrease in the navicular drop height in all the groups which was statistically significant. While in Group $C$, the linear distance of the foot post treatment was statistically significant. There was no change in the arch index post the intervention in mobilization, low dye taping and faradic foot bath groups. The intergroup comparison results showed no statistical significance in all the parameters.
\end{abstract}

Conclusion: Talo-navicular mobilization, low dye taping and faradic foot bath were equally effective in reducing the navicular drop height and the arch index in subjects with flat foot.

Key words: flat foot, mobilization, low dye taping, faradic foot bath, exercises

\section{Introduction}

The foot is the terminal joint in the lower kinetic chain and the body weight is borne through two halfcolumns of the foot with the medial border of each foot raised from the ground. ${ }^{\mathrm{T}}$ The arch is controlled by the combined action of talonavicular joint and the subtalar joint which helps in the interaction between leg and foot rotations. Flat feet also known as pes planus, is a foot deformity in which there is a reduction in the medial longitudinal arch of the foot. There are many causes of pes planus which may be congenital or it may also result from trauma, muscle weakness, ligament laxity, dropping of the talar head, paralysis or pronated foot. Flat foot may occur in up to $20 \%$ of adults, out of which many have flexible and asymptomatic flat feet. A study was conducted in India on normal healthy volunteers between the age group of 25 to 40 years, it was observed that the prevalence of flat feet was $24.59 \%$ in males and $22.04 \%$ in females. $^{2}$

Flat foot is further classified as flexible or functional and rigid or structural flat foot. Individuals with functional flat foot have a reduced medial arch of the foot during weight bearing while in those with structural flat foot, the weight bearing status of the foot does not affect the arch.

The function and structure of the arch depends on the shape of the foot, bony structure, ligamentous stability and muscular fatigue while factors like race, footwear, age and gender are also found to influence the formation of medial longitudinal arch. ${ }^{3}$ The integrity of the arches depends primarily on the ligamentous support with assistance from bony alignment and additional support from the extrinsic muscles of the foot. The plantar fascia, long and short plantar ligaments, the spring ligament, the collateral ligaments of the ankle and the interosseous ligament of the subtalar joint; all contribute important soft tissue support to the arches of the foot. ${ }^{4}$

Electromyographic studies done on the muscles of the leg and foot have shown that loads of 100 to 200 pounds on one foot are borne easily by passive structures such as ligaments and bones that support the arches. Initially, on loading the activity of ligamentous structures comes into play while the muscles form a dynamic 
reserve. As the load is increased upto 400 pounds, the muscles do come into play, but even then many of them remain inactive. ${ }^{5}$

The foot posture should be considered when assessing patients with musculoskeletal disorders. A study conducted to evaluate effect of flatfoot on the pelvis posture of subjects showed that those with bilateral and unilateral second degree flatfoot had changes in the pelvic alignment. ${ }^{6}$ As the degree of pes planus deformity increases, the degree of static postural stability of an individual also decreases. ${ }^{7}$ Studies have linked flat feet, ankle instability, sagittal plane blockage and excessive pronation to low back pain due to the disruption of the kinetic chain from the foot to the back. ${ }^{8}$

There are many techniques to measure the medial longitudinal arch (MLA). Clinical measurements of Arch Index (AI), Navicular Height (NH) and Foot Posture Index (FPI) provide valid information regarding the structure of the medial longitudinal arch. ${ }^{9}$

There are many treatments available for flat foot which include strengthening of the intrinsic and extrinsic muscles of foot, stretching of the Achilles tendon, taping and orthosis or use of wedge to correct the foot posture, mobilizing the bones of the midfoot and faradic stimulation for the foot.

The purpose of this study was to find the comparative effect of talo-navicular mobilization, low dye taping and faradic foot bath in subjects with flat foot. In flat foot, since the foot is pronated mobilization has to be given in order to improve or increase the medial arch. ${ }^{10}$ A study has shown that low dye taping for the foot has immediate effects on navicular bone and it has reported to increase the arch height by $8-16 \% .{ }^{11}$ There is paucity of literature on faradic stimulation for the intrinsic muscles of the foot in subjects with flat foot. So, a comparative effect of these treatments on the navicular height and arch index in subjects with flat foot was done to find out which one was superior to the other.

\section{Method}

An approval for the study was obtained from the Institutional Ethical Committee. 51 subjects aged between 18 to 30 years, both males and females, with unilateral or bilateral involvement, having functional flat feet with navicular drop test positive ${ }^{12}$ and arch index $>0.26{ }^{13}$ were included. Exclusion consisted of history of fractures in the lower limb, skin infections and wounds on the foot, tape allergies, any neurological deficit and peripheral vascular diseases. The subjects were randomly allocated, with 17 subjects in each group and were assigned to 3 groups: Talo-navicular mobilization (Group A), Low dye taping (Group B) and Faradic foot bath (Group C). Demographic data was collected and navicular drop test and arch index was measured pre and post the 3 weeks intervention. Treatment was given for 5 days a week for 3 weeks.

Subjects in Group A were given talo-navicular mobilization and conventional exercises. In talonavicular mobilization, a plantar glide of 20 repetitions of 3 sets was given to the navicular while stabilizing the talar neck. ${ }^{10}$

Subjects in Group B received low dye taping for the foot following which they had to perform the conventional exercises. Tape was applied with the subject in prone with the ankle in neutral position and the foot was maintained at $90^{\circ}$. Longitudinal anchor strips was applied along the lateral aspect of the $5^{\text {th }}$ metatarsal going to the hind foot, around the calcaneum and then progressed to the medial aspect of the foot along the $1^{\text {st }}$ metatarsal on the plantar aspect of the foot. The transverse arch support strips were applied by pulling from lateral border to the medial border of the foot along the plantar surface and the area from the anterior surface of the calcaneum to the metatarsal heads was covered. The transverse strips were locked in the same method as the longitudinal anchor strips. Tape was changed every 3 days. ${ }^{11}$

Subjects in Group C were given faradic foot bath and conventional exercises. The placement of the electrodes was, one at the heel and the other at the metatarsal heads to stimulate the intrinsic muscles of the foot. ${ }^{14}$ During the stimulation, the subjects had to actively perform toe curls and 30 contractions of 3 sets were given.

Conventional exercises included toe curls, foot inversion - eversion, toe and heel raises. 10 repetitions of each exercise were performed.

\section{Statistical analysis}

Statistical analysis was done using R software version 3.3.1. Data was collected and analysed using Paired t test, to find out the statistical significance within the groups post treatment which was assessed on the basis of $\mathrm{p}$ value which should be $\leq 0.05$. Data was collected and analysed using ANOVA to find out the statistical significance between the groups which was assessed on the basis of $\mathrm{p}$ value which should be $\leq 0.05$. The parameters used were navicular height, linear distance of the foot and arch index. A 95\% confidence interval was considered in all the tests. 


\section{Results}

As seen in Table 1, the demographic data of all the subjects showed homogeneity. A mean change in the navicular drop height of $3.71 \pm 0.42 \mathrm{~mm}, 4.29 \pm 0.63 \mathrm{~mm}$ and $4.76 \pm 1.18 \mathrm{~mm}$ was seen in the groups A, B and C respectively as seen in Tables 2, 3 and 4. On comparing the mean scores for the navicular drop height, linear distance of the foot and arch index between the groups by ANOVA, it showed that the $\mathrm{p}$ value was not significant (Tables 5,6,7). It can be further concluded that all the groups were equally effective.

Table 1: Demographic data

\begin{tabular}{|c|c|c|c|c|}
\hline Parameter & $\begin{array}{c}\text { Group A } \\
\mathbf{n}=17\end{array}$ & $\begin{array}{c}\text { Group B } \\
n=17\end{array}$ & $\begin{array}{c}\text { Group C } \\
\mathbf{n}=17\end{array}$ & $\begin{array}{c}\mathbf{P} \\
\text { Value }\end{array}$ \\
\hline Age (yrs) & $22.71 \pm 2.93$ & $22.47 \pm 3.16$ & $21.76 \pm 2.33$ & 0.60 \\
\hline Weight (kgs) & $68.70 \pm 18.71$ & $61.2 \pm 15.7$ & $58.8 \pm 14.3$ & 0.19 \\
\hline Height (cm) & $169.28 \pm 8.95$ & $163.2 \pm 11.99$ & $164.2 \pm 13.15$ & 0.26 \\
\hline $\begin{array}{c}\text { BMI } \\
\left(\mathrm{Kg} / \mathbf{m}^{2}\right)\end{array}$ & $24.87 \pm 5.44$ & $23.7 \pm 5.41$ & $23.38 \pm 4.87$ & 0.68 \\
\hline
\end{tabular}

$\mathrm{p}$ value $\leq 0.05$

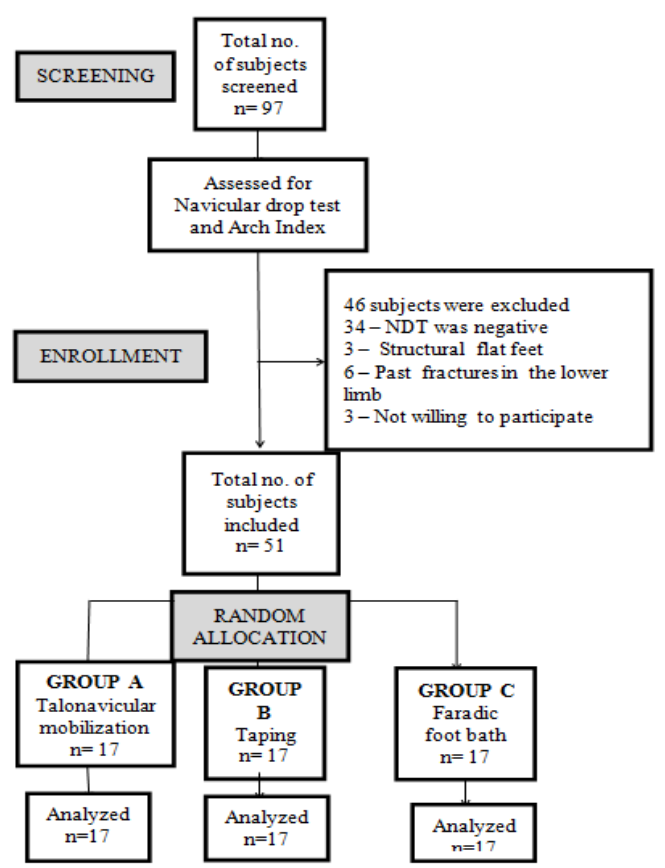

Figure 1: Flowchart of the study

Table 2: Group A - Comparison of Talonavicular Mobilization group using Paired t test

\begin{tabular}{|c|c|c|c|c|}
\hline \multirow{2}{*}{ Parameter } & \multicolumn{2}{|c|}{ Mean \pm SD } & \multirow{2}{*}{$\begin{array}{c}\text { p value } \\
\text { value }\end{array}$} & \\
\cline { 2 - 3 } & $11.58 \pm 1.00$ & $7.88 \pm 1.86$ & 7.66 & $0.0000005^{*}$ \\
\hline $\begin{array}{c}\text { Navicular drop } \\
\text { height (mm) }\end{array}$ & $66.48 \pm 5.60$ & $66.05 \pm 5.57$ & 0.73 & 0.237 \\
\hline $\begin{array}{c}\text { Linear distance of } \\
\text { the foot (mm) }\end{array}$ & $0.33 \pm 0$ & $0.33 \pm 0$ & - & - \\
\hline Arch index ${ }^{\mathrm{a}}$ & \multicolumn{2}{|c}{} \\
\hline
\end{tabular}

$* \mathrm{p}$ value $<0.05$

${ }^{\mathrm{a}}$ Since the pre and post value were same, the results could not be computed. 
Table 3: Group B - Comparison of Low dye taping group using Paired t test

\begin{tabular}{|c|c|c|c|c|}
\hline \multirow{2}{*}{ Parameter } & \multicolumn{2}{|c|}{ Mean \pm SD } & t value & p value \\
\cline { 2 - 3 } \cline { 5 - 5 } & Pre & Post & & \\
\hline Navicular drop height $(\mathrm{mm})$ & $11.94 \pm 1.08$ & $7.64 \pm 2.37$ & 7.84 & $0.0000003^{*}$ \\
\hline Linear distance of the foot $(\mathrm{mm})$ & $63.21 \pm 4.34$ & $62.57 \pm 4.30$ & 1.57 & 0.13 \\
\hline Arch index & $0.33 \pm 0$ & $0.329 \pm 0.002$ & 1 & 0.3321 \\
\hline
\end{tabular}

$* \mathrm{p}$ value $\leq 0.05$

Table 4: Group C - Comparison of Faradic Foot Bath group using Paired $t$ test

\begin{tabular}{|c|c|c|c|c|}
\hline \multirow{2}{*}{ Parameter } & \multicolumn{2}{|c|}{ Mean \pm SD } & t value & \multirow{2}{*}{ p value } \\
\cline { 2 - 5 } & Pre & Post & & \\
\hline Navicular drop height $(\mathrm{mm})$ & $12 \pm 1.36$ & $7.23 \pm 2.56$ & 8.14 & $0.0000002^{*}$ \\
\hline Linear distance of the foot $(\mathrm{mm})$ & $64.48 \pm 5.06$ & $63.3 \pm 4.88$ & 2.16 & $0.02308^{*}$ \\
\hline Arch index & $0.33 \pm 0$ & $0.329 \pm 0.002$ & 1 & 0.332 \\
\hline
\end{tabular}

$* \mathrm{p}$ value $\leq 0.05$

Table 5: Summary table for analysis of variance for mean change in the navicular height.

\begin{tabular}{|l|c|c|c|c|c|c|}
\hline Source of Variation & $S S$ & $d f$ & $M S$ & $F$ & $p$-value & $F$ crit \\
\hline Between Groups & 9.56 & 2 & 4.78 & 0.96 & 0.38 & 3.19 \\
\hline Within Groups & 238.11 & 48 & 4.96 & & & \\
\hline Total & 247.68 & 50 & & & & \\
\hline
\end{tabular}

Table 6: Summary table for analysis of variance for mean change in the linear distance of the foot.

\begin{tabular}{|c|c|c|c|c|c|c|}
\hline Source of Variation & $S S$ & $d f$ & $M S$ & $F$ & $p$-value & $F$ crit \\
\hline Between Groups & 0.05 & 2 & 0.02 & 0.56 & 0.57 & 3.19 \\
\hline Within Groups & 2.18 & 48 & 0.04 & & & \\
\hline Total & 2.24 & 50 & & & & \\
\hline
\end{tabular}

Table 7: Summary table for analysis of variance for mean change in the arch index.

\begin{tabular}{|c|c|c|c|c|c|c|}
\hline Source of Variation & $S S$ & $d f$ & $M S$ & $F$ & $p$-value & $F$ crit \\
\hline Between Groups & 0.000004 & 2 & 0.000002 & 0.5 & 0.60 & 3.19 \\
\hline Within Groups & 0.00018 & 48 & 0.000004 & & & \\
\hline Total & 0.000192 & 50 & & & & \\
\hline
\end{tabular}

\section{Discussion}

In the present study asymptomatic individuals with flat feet were included; since in a National Health Survey of 1990, it was suggested that the prevention or treatment of flat feet reduces the incidence of calluses, bunion, hammertoe and arthritis. ${ }^{15}$ There are also many biomechanical alterations in the body due to flat foot which further affects the general health of an individual. Individuals with asymptomatic flat feet need to absorb more negative ankle joint energy during loading response of gait which leads to fatigue and overuse syndrome of the anterior shank muscles. ${ }^{16} \mathrm{~A}$ Framingham Foot and Osteoarthritis study done on 2,000 participants, found a statistically significant increase in medial knee pain $(1.3$ times) and medial knee joint cartilage damage (1.4 times) in those with planus foot morphology. ${ }^{17}$

Conventional exercises of toe curls, heel and toe raises, inversion and eversion of the foot was incorporated in all the 3 groups in order to exclusively find out the additive effects of the interventions. Foot exercises have been shown to increase the navicular height as exercises strengthen the elevator muscles in the foot. These exercises also help in improving the strength of the intrinsic and extrinsic muscles of foot.

The talo-navicular joint is responsible for translating inversion and eversion movements of the subtalar joint to the midfoot. When a foot is pronated the navicular drops which causes the talus to shift and this causes a length - tension deficit of the tibialis posterior tendon which is attached to the navicular bone of the foot. ${ }^{18}$ Mobilization of the talo-navicular joint helps via the proprioceptors in improving the joint dysfunction which has occurred due to improper or poor posture. Joint dysfunction if left untreated may affect the surrounding soft tissue and may also lead to reduction in strength, flexibility as well as cause an abnormal strain on other joints. ${ }^{19}$ These alterations in the foot has been considered and thus, mobilizing the navicular bone must have improved the medial arch by increasing the navicular height. 
Low dye taping is said to act by controlling pronation of the foot by pulling the calcaneus anteriorly and medially, thus limiting hindfoot eversion and restricting the associated talar adduction and plantarflexion. When the subtalar motion is limited, the arch is elevated subsequently reducing the stretch on the plantar aponeurosis. Similarly, the medial arch height is raised as the tape pulls the lateral aspect of the foot medially. ${ }^{20}$

Studies have shown that electrical stimulation of frequencies above $60 \mathrm{~Hz}$ helps in improving the muscular strength. ${ }^{21,22}$ The results of the present study demonstrated the results defined by Lainey CG Walmsley RP and Andrew GM about the effectiveness of exercise plus electrical stimulation compared to that of exercise alone, for increasing the strength of the quadriceps muscle in 6 males and 2 female patients following knee surgery. No significant differences in strength gains were found but the results suggested that electrical stimulation may be a valuable adjunct to exercise in the development of muscle strength in individuals who have undergone knee surgery, particularly after the initial postoperative period. ${ }^{23}$

Fatigue of the intrinsic muscles of the foot increases foot pronation and thus, the pronation of the foot may be controlled by improving the strength of the muscles by faradic stimulation. ${ }^{24}$ Since the medial arch height of the foot increased, it may have caused a reduction in the linear distance of the foot post intervention. The arch index almost had a negligible change post the intervention in all the groups. This may be due to the minimal change in the linear distance of the foot and it may have affected the arch index ratio of the foot which was calculated.

Based on the results obtained in the present study, it showed that faradic foot bath was more effective followed by low dye taping and talo-navicular mobilization but statistically there was no difference found between the three groups. The limitations of the study were that the long term effects were not evaluated and individuals with age above 30 years were not included. The future scope of the study could be compared between symptomatic and asymptomatic individuals with flat foot, the long term effects could be evaluated in homogenous and heterogenous population with equal distribution and a comparison between individuals with structural and functional flat foot could be studied.

\section{Conclusion}

The intra group comparison results showed a decrease in the navicular drop height in all the groups which was statistically significant. While in the Group $\mathrm{C}$, the linear distance of the foot post treatment was statistically significant. There was no change in the arch index post the intervention in mobilization, low dye taping and faradic foot bath groups. The intergroup comparison results showed no statistical significance in all the parameters. The percentage change in the navicular drop height post the intervention in Group A was $32.03 \%$, in Group B was $35.92 \%$ and in Group C was 39.66\%. A mean change in the arch index was 0 in Group A, $0.0005 \pm 0.002$ in Group B and $0.0005 \pm 0.002$ in Group C. The talo-navicular mobilization, low dye taping and faradic foot bath were equally effective in reducing the navicular drop height in subjects with flat foot.

\section{Acknowledgement}

We express our sincere gratitude to all the subjects who participated in this study. We are also grateful to the hospital and management staff of KLE's Universities Institute of Physiotherapy for allowing us to conduct this study.

\section{References}

[1] Jones F Wood. Structure and Function as seen in the Foot. Ulster Med J. 1944 May;13(1):4.

[2] K Vijayakumar, S Senthilkumar, Rameshkumar Subramanian. A study on relationship between BMI and prevalence of flat foot among the adults using foot print parameters. International Journal of Advanced Research. 2016; 4(5):1428-1431.

[3] Rasmus G Nielsen, Michael S Rathleff, Ole H Simonsen, Henning Langberg. Determination of normal values for navicular drop during walking: a new model correcting for foot length and gender. J Foot Ankle Res. 2009; 2: 12.

[4] Available from: http://www.foothyperbook.com/elective/flatfoot/flatfootbiomechanics.htm

[5] John V. Basmajian, George Stecko. The Role of Muscles in Arch Support of the Foot. An Electromyographic Study. J Bone Joint Surg Am. 1963 Sep; 45 (6): 1184-1190.

[6] Colin B O’Learya, Caroline R Cahilla, Andrew W Robinsona, Meredith J Barnesa and Junggi Hong. A systematic review: The effects of podiatrical deviations on nonspecific chronic low back pain. Journal of Back and Musculoskeletal Rehabilitation. 2013; 26:117-123.

[7] Nadir Yalçin, Erdinç Esen, Ulunay Kanatli, Haluk Yetkin. Evaluation of the medial longitudinal arch: a comparison between the dynamic plantar pressure measurement system and radiographic analysis. Acta Orthop Traumatol Turc. 2010;44(3):241-245.

[8] J McCrory, M Young, A Boulton, P Cavanagh. Arch index as a predictor of arch height. The Int J of Foot Clin Sci.1997 June; 7(2):79-81.

[9] Hylton B Menz, Shannon E Munteanu. Validity of 3 Clinical Techniques for the Measurement of Static Foot Posture in Older People. J Orthop Sports PhysTher. 2005;35:479-486.

[10] Janice K Loudon, Stephania L Bell. The Foot and Ankle: An Overview of Arthrokinematics and Selected Joint Techniques. Journal of athletic training. 1996 June; Volume 31.

[11] Seung-Min Lee, Dong-Yeop Lee, Ji-Heon Hong, Jae-Ho Yu and Jin-Seop Kim. The effect of elastic and non-elastic tape on flat foot. Indian Journal of Science and Technology. 2015 October ; 8( 26).

[12] David J. Magee. Orthopedic Physical Assessment. $5^{\text {th }}$ edition:2008. Saunders Elsevier. p 844-884. 
[13] Hironmoy Roy, Kalyan Bhattacharya, Samar Deb, Kuntala Ray. Arch index: An easier approach for arch height. Al Ameen $J$ Med Sci. 2012;137-146.

[14] Forster \& Palastanga. Clayton's Electrotherapy. $8^{\text {th }}$ edition:2005. p 49-61.

[15] Shibuya MS, Jupiter DC, Ciliberti LJ, Vincent VanBuren, Javier La Fontaine. Characteristics of adult flatfoot in the United States. $J$ Foot Ankle Surg. 2010; 49(4):363-368.

[16] Matthias Hösl, Harald Böhm, Christel Multerer, Leonhard Döderlein. Does excessive flatfoot deformity affect function? A comparison between symptomatic and asymptomatic flatfeet using the Oxford Foot Model. Gait \& Posture Jrnl.2014 January; 39(1): 23-28.

[17] Borrelli AH. Planar dominance. A major determinant in flatfoot stabilization. Clin Podiatr Med Surg.1999;16(3):407-21

[18] Available from : https://barefootstrongblog.com/2015/05/22/the-functional-impact-of-navicular-drop/

[19] Available from: http://www.pt-works.com/joint-mobilization.asp

[20] Robert Yoho, Julian J Rivera, Robert Renschler, Vassilios G Vardaxis, Jeffrey Dikis. A biomechanical analysis of the effects of low dye taping on arch deformation during gait. The Foot. 2012;22:283-286.

[21] Available from :

http://www.itechmedicaldivision.com/en/muscular_stimulation_types_of_frequencies_and_effects_-t-7.html

[22] D P Currier and Ralph Mann. Muscular strength development by electrical stimulation in healthy individuals. PHYS THER. 1983; 63:915-921.

[23] Lainey CG, Walmsley RP, Andrew GM. Effectiveness of exercise alone versus exercise plus electrical stimulation in strengthening the quadriceps muscle. Physiotherapy Canada. 1983 Jan-Feb;35(1):5-11.

[24] Headlee DL, Leonard JL, Hart JM, Ingersoll CD, Hertel J. Fatigue of the plantar intrinsic foot muscles increases navicular drop. $J$ Electromyogr Kinesiol. 2008 Jun;18(3):420-5. 